\title{
Novel zinc phthalocyanine as a promising photosensitizer for photodynamic treatment of esophageal cancer
}

\author{
WERONIKA KUZYNIAK ${ }^{1}$, JACOB SCHMIDT ${ }^{1}$, WOJCIECH GLAC ${ }^{2}$, JANINE BERKHOLZ ${ }^{1}$, \\ GUSTAV STEINEMANN $^{1}$, BJÖRN HOFFMANN ${ }^{1}$, EUGENY A. ERMILOV ${ }^{3,4}$, AYŞE GÜL GÜREK ${ }^{5}$, \\ VEFA AHSEN $^{5}$, BIANCA NITZSCHE $^{1 *}$ and MICHAEL HÖPFNER ${ }^{1 *}$ \\ ${ }^{1}$ Institute of Physiology, Charité-Universitätsmedizin Berlin, Berlin, Germany; ${ }^{2}$ Department of Animal \\ and Human Physiology, Faculty of Biology, University of Gdansk, Gdansk, Poland; \\ ${ }^{3}$ Federal Institute for Materials Research and Testing (BAM), Division Biophotonics; \\ ${ }^{4}$ Institute of Physics, Humboldt-Universität zu Berlin, Berlin, Germany; \\ ${ }^{5}$ Department of Chemistry, Gebze Technical University, Gebze, Turkey
}

Received November 9, 2016; Accepted December 19, 2016

DOI: 10.3892/ijo.2017.3854

\begin{abstract}
Photodynamic therapy (PDT) has gathered much attention in the field of cancer treatment and is increasingly used as an alternative solution for esophageal cancer therapy. However, there is a constant need for improving the effectiveness and tolerability of the applied photosensitizers (PS). Here, we propose tetra-triethyleneoxysulfonyl substituted zinc phthalocyanine $(\mathrm{ZnPc})$ as a promising PS for photodynamic treatment of esophageal cancer. ZnPc-induced phototoxicity was studied in two human esophageal cancer cell lines: OE-33 (adenocarcinoma) and Kyse-140 (squamous cell carcinoma). In vitro studies focused on the uptake and intracellular distribution of the novel $\mathrm{ZnPc}$ as well as on its growth inhibitory potential, reactive oxygen species (ROS) formation and the induction of apoptosis. The chicken chorioallantoic membrane assay (CAM assay) and studies on native Wistar rats were employed to determine the antineoplastic and antiangiogenic activity of ZnPc-PDT as well as the tolerability and safety of non-photoactivated $\mathrm{ZnPc}$ in vivo. $\mathrm{ZnPc}$ was taken up by cancer cells in a dose- and time-dependent manner and showed a homogeneous cytoplasmic distribution. Photoactivation of ZnPc-loaded (1-10 $\mu \mathrm{M})$ cells led to a dose-dependent growth inhibition of esophageal adenocarcinoma and squamous cell carcinoma cells of $>90 \%$. The antiproliferative effect was based on ROS-induced cytotoxicity and the induction of
\end{abstract}

Correspondence to: Professor Michael Höpfner, Institute of Physiology, Charité-Universitätsmedizin Berlin, Charitéplatz 1, D-10117 Berlin, Germany

E-mail: michael.hoepfner@charite.de

"Joint senior authorship

Key words: zinc phthalocyanine, photodynamic therapy, esophagus cancer, reactive oxygen species mitochondria-driven apoptosis. In vivo studies on esophageal tumor plaques grown on the CAM revealed pronounced antiangiogenic and antineoplastic effects. ZnPc-PDT caused long-lasting changes in the vascular architecture and a marked reduction of tumor feeding blood vessels. Animal studies confirmed the good tolerability and systemic safety of $\mathrm{ZnPc}$, as no changes in immunological, behavioral and organic parameters could be detected upon treatment with the nonphotoactivated $\mathrm{ZnPc}$. Our findings show the extraordinary photoactive potential of the novel $\mathrm{ZnPc}$ as a photosensitizer for PDT of esophageal cancer.

\section{Introduction}

Each year an increasing number of patients is diagnosed with esophageal cancer, which makes it the eight most common cancer worldwide. With almost 500,000 new cases diagnosed and 400,000 deaths in 2012, esophageal cancer is the sixth most common cause of cancer-related death worldwide. The overall 5 -year survival rate for patients diagnosed with esophageal cancer is $<20 \%$ and the current treatment options are far from being satisfactory (1-4). Therefore, innovative approaches are urgently needed (5). In this respect, photodynamic therapy (PDT) has emerged as an effective and supporting modality for gastroenterological and dermatological treatment and has already been shown to be a promising and clinically relevant treatment modality for esophageal neoplasia (6-8).

PDT involves the activation of a photosensitizing drug by irradiation to locally generating reactive oxygen species (e.g., singlet oxygen and superoxide anion radicals) which induces tumor shrinkage by apoptosis and/or necrosis $(9,10)$. Recent developments in synthetic chemistry and optics created new perspectives for the enhancement of the PDT as a promising treatment option. Phthalocyanines are very interesting photoactive substances, which are currently intensively investigated (11-13).

Here, we propose tetra-triethyleneoxysulfonyl substituted zinc phthalocyanine $(\mathrm{ZnPc})$ as a promising photosensitizer for 
PDT of esophageal cancer. Results of a previous in vitro study already demonstrated a long-lasting elimination of cancer cells of different origin (e.g., pancreatic carcinoid, colorectal carcinoma) (14). This study focused on the photodynamic treatment of esophageal cancer and took both entities, namely squamous cell carcinoma and adenocarcinoma into account to evaluate the potential of this novel $\mathrm{ZnPc}$ as a candidate for future PDT treatment of esophageal cancer.

\section{Materials and methods}

Photosensitizer. Tetra-triethyleneoxysulfonyl substituted zinc phthalocyanine $(\mathrm{ZnPc})$ was prepared by slightly modifying the procedure described in the literature (15). The compound was dissolved in DMSO of spectroscopic grade (Sigma-Aldrich, France). Concentration of stock solutions was calculated by measuring their optical density at $694 \mathrm{~nm}$ with UV/Vis spectrometer Ultraspec 2100 (Amersham Biosciences, UK) and based on Lambert-Beer relationship with $\varepsilon_{694 \mathrm{~nm}}=2.04 \times 10^{5} \mathrm{M} / \mathrm{cm}$ (14).

Cell culture. The human esophageal squamous carcinoma cell line Kyse-140 and the human esophageal adenocarcinoma cell line OE-33 were cultured in RPMI-1640 medium (Gibco, Thermo Fisher Scientific, Germany) supplemented with $10 \%$ fetal bovine serum (FCS, Biochrom AG, Germany), $100 \mathrm{U} / \mathrm{ml}$ penicillin and $100 \mu \mathrm{g} / \mathrm{ml}$ streptomycin (Biochrom AG) $(5,9)$. Medium of OE-33 cells was additionally supplemented with $2 \mathrm{mM}$ L-glutamine (Biochrom AG). All cells were kept under standard conditions $\left(37^{\circ} \mathrm{C}\right.$ in a humidified atmosphere of $5 \% \mathrm{CO}_{2}$ ). The culture medium was changed every second day and once a week the cells were passaged using $1 \%$ trypsin/EDTA.

Light source and irradiation. Cancer cells were irradiated with a broad band light source equipped with a $100 \mathrm{~W}$ halogen lamp (EFR 12 V/100 W GZ - 6.35 lamp, Omnilux, Germany). The spectral output of the lamp ranged from 400 to $800 \mathrm{~nm}$. To prevent infrared irradiation, a heat-reflecting filter that cuts off transmission at $700 \mathrm{~nm}$ and above was inserted into the optical path. The illuminated area $(5.5 \times 4.5 \mathrm{~cm})$ had an average power density of $80 \mathrm{~W} / \mathrm{m}^{2}$. The light energy dose was measured with a P-9710 radiometer controlled by a silicon photocell (Optometer P 9710) from Gigahertz-Optik (Munich, Germany). The total light energy dose was calculated by integrating the energy signal over the entire period of irradiation.

Photodynamic therapy. For PDT treatment cells were incubated with $\mathrm{ZnPc}(1-10 \mu \mathrm{M})$ for $1-30 \mathrm{~h}$ in the dark at $37^{\circ} \mathrm{C}\left(5 \% \mathrm{CO}_{2}\right.$, humidified atmosphere). Thereafter, the ZnPc-containing medium was replaced by PBS, and cells were irradiated with a light dose of $10 \mathrm{~J} / \mathrm{cm}^{2}$. During irradiation the temperature of the samples never exceeded $37^{\circ} \mathrm{C}$ (temperature was measured with a digital thermometer placed inside of irradiation system). After irradiation PBS was removed and cells were maintained at $37^{\circ} \mathrm{C}$ in the incubator $\left(5 \% \mathrm{CO}_{2}\right.$, humidified atmosphere) in PS-free culture medium. Cytotoxic effects of the PS in the absence of light (dark controls) were determined by treating the samples in the same way except for the irradiation.
Intracellular distribution of ZnPc. Cells grown on glass cover slips, were incubated with increasing concentrations of nonphotoactivated $\mathrm{ZnPc}(1-10 \mu \mathrm{M})$ for $24 \mathrm{~h}$ and then analyzed by measuring their fluorescence with a confocal laser microscope (Leica, DMI 6000, Germany) [excitation: HeNe laser (633 nm), detection: PMT (400-800 nm)], equipped with 63x glycerin immersion objective. Digital images were processed using the Leica LAS AF Lite software.

Growth inhibitory effects of ZnPc-PDT. Changes in the cell number were investigated by performing crystal violet staining as described previously (16). Briefly, the cells were fixed with $1 \%$ glutaraldehyde and stained with $0.1 \%$ crystal violet. The unbound dye was removed by washing the cells with water. Bound crystal violet was solubilized with $0.2 \%$ Triton-X-100 in PBS. Light extinction, which increases linearly with the cell number, was analyzed at $570 \mathrm{~nm}$ using an ELISA-Reader.

Measurement of reactive oxygen species (ROS). Cells were incubated for $24 \mathrm{~h}$ with $\mathrm{ZnPc}$, and then illuminated with $10 \mathrm{~J} / \mathrm{cm}^{2}$. ROS formation was determined $24 \mathrm{~h}$ later with CellROX Green and CellROX Orange (Thermo Fisher Scientific, USA) according to the manufacturer's protocol. Control cells underwent PDT without previous ZnPc loading. Cells were analyzed by using a fluorescence microscope (Axioskop 40; objective 40x, NA 1.30, Zeiss, Germany) equipped with digital camera (Kappa, DX4-285FW, Germany). Green fluorescence shows ROS formation in nucleus and mitochondria (ex/ em $\sim 470 / 525 \mathrm{~nm}$ ), orange fluorescence displays ROS in the cytoplasm (ex/em $\sim 546 / 575 \mathrm{~nm}$ ). Separate sets of cells were incubated with $1 \mathrm{mM}$ of vitamin C (WEPA, Germany) for $1 \mathrm{~h}$ before ZnPc-PDT to suppress ROS formation.

Detection of apoptosis. Changes in caspase-3 activity were calculated from the cleavage of the fluorogenic substrate AC-DEVD-AMC (Calbiochem-Novabiochem, Germany), as described previously (17). Three and $6 \mathrm{~h}$ after ZnPc-PDT, cells were lysed with lysis buffer and the lysates were incubated for $1 \mathrm{~h}$ at $37^{\circ} \mathrm{C}$ with a substrate solution containing $20 \mu \mathrm{g} / \mathrm{ml}$ AC-DEVD-AMC, 20 mM HEPES, 10\% glycerol, 2 mM DTT at $\mathrm{pH}$ 7.5. Substrate cleavage was measured fluorometrically using a VersaFluor fluorometer (Bio-Rad, Germany; filter sets: ex 360/40 nm, em 460/10 nm).

Detection of apoptosis-specific changes in cellular morphology were visualized by using cell viability/cytotoxicity assay kit (Live/dead assay, Life Technologies, USA) as described earlier (18). Six hours after ZnPc-PDT, cells which were grown on cover slips, were incubated with calceinAM $(160 \mathrm{nM})$ and EthD-1 $(2 \mu \mathrm{M})$ for $30 \mathrm{~min}$ in medium at $37^{\circ} \mathrm{C}$ and examined by fluorescence microscope from Zeiss (Axioskop 40; objective 20x, 0.50 NA, Zeiss). Live cells were identified by the presence of ubiquitous intracellular esterase activity, leading to the conversion of non-fluorescent cell-permeable calcein-AM to the green-fluorescent polyanionic dye calcein (ex/em 495/510 nm), which is well retained in living cells. Dead cells were determined by EthD-1 (ex/em 495/635 nm), which becomes red-fluorescent upon binding to nucleic acids of cells with damaged membranes.

Changes in Bcl-2 and Bax expression, and release of cytochrome $c$ from PDT-damaged mitochondria, indicating 
the induction of mitochondria mediated apoptosis was analyzed by western blotting as described previously (19). In brief, whole-cell extracts were prepared by lysing cells with RIPA-buffer. Cell lysates containing $30 \mu \mathrm{g}$ protein were subjected to gel electrophoresis (12\% gel for Bcl-2 and Bax, 4-20\% gel for cytochrome $c$, Bio-Rad, USA). Proteins were transferred to PVDF membranes by electroblotting for $1.5 \mathrm{~h}$ at $100 \mathrm{~V}$. The blots were blocked in 5\% non-fat dry milk in TBS-Tween solution for $1 \mathrm{~h}$ at room temperature, and then incubated at $4{ }^{\circ} \mathrm{C}$ overnight with antibodies directed against anti-human Bcl-2 (1:500) (Santa Cruz, USA), Bax (1:500) (Cell Signaling, USA), cytochrome $c(1: 1,000)$ (Cell Signaling) and anti- $\beta$-actin $(1: 2,000)$ (Sigma, USA) as loading control. After incubation with horseradish peroxidase-coupled anti-IgG antibodies (1:10,000, Amersham) for $\geq 1 \mathrm{~h}$ at room temperature, the blots were developed and visualized by using enhanced chemiluminescent detection kit (Amersham) and exposed to ECL Hyperfilm.

Antitumoral and antiangiogenic effects of ZnPc-PDT. In vivo studies on the antitumoral and antiangiogenic effects of ZnPc-PDT were performed by using chicken chorioallantoic membrane assays (CAM) as described previously $(14,20)$.

Kyse-140 cells $\left(1 \times 10^{6}\right)$ were resuspended in $10 \mu \mathrm{l}$ cell culture medium and mixed with $10 \mu \mathrm{l}$ Matrigel (Corning, MA, USA). Cell suspensions were pipetted into silicone ring $(5 \mathrm{~mm} \varnothing)$ that was placed on the CAM of fertilized chicken eggs on day 7 of development. The tumor plaques were allowed to adhere for $72 \mathrm{~h}$ before they were topically treated with $10 \mu \mathrm{l}$ of $\mathrm{ZnPc}(10 \mu \mathrm{M})$ or $\mathrm{NaCl} 0.9 \%$ (as negative control). Thereafter eggs were sealed with clear tape and incubated in the dark at $37^{\circ} \mathrm{C}$ in a humidified incubator. Twenty-four hours later tumors were illuminated with $10 \mathrm{~J} / \mathrm{cm}^{2}$. Tumor growth and viability of the developing embryo were controlled daily by stereo microscopy (up to $72 \mathrm{~h}$ after treatment). At the end of the experiment, tumors were resected, measured - (largest diameter $)^{2} \mathrm{x}$ (perpendicular diameter) $\mathrm{x} 0.5$ and photographed with stereo-microscope equipped with camera (Di-Li, digital microscope, Germany) (21).

For the antiangiogenic testing of ZnPc-PDT, $10 \mu \mathrm{l}$ of $\mathrm{ZnPc}(10 \mu \mathrm{M})$ or $10 \mu \mathrm{l} \mathrm{NaCl} 0.9 \%$ (as negative control) were topically applied inside of a silicone ring $(5 \mathrm{~mm} \varnothing)$ that was placed on the CAM of fertilized chicken eggs at day 11 of the chicken embryo development. Thereafter eggs were sealed with clear tape and incubated in the dark at $37^{\circ} \mathrm{C}$ in a humidified incubator. Twenty-four hours later the treated areas were illuminated with $10 \mathrm{~J} / \mathrm{cm}^{2}$. Changes in the microvasculature of the CAM were recorded 24 and $72 \mathrm{~h}$ after PDT by using a stereo microscope (Axioplan; Zeiss) equipped with a digital camera (MBF, Bioscience, USA).

Biotolerability of non-photoactivated ZnPc in vivo. Safety of non-photoactivated $\mathrm{ZnPc}$ in vivo was examined in male Wistar rats (n=15, weight $290 \pm 6 \mathrm{~g}$; 11-week-old) (22). Influence of the PS on the immune system and organs such as liver or kidneys were examined to monitor the potential dark toxicity of the compound. Rats were divided into four treatment groups: group I, negative control, $0.9 \%$ saline, $\mathrm{n}=3$; groups II-IV, 0.5 , 1 and $5 \mathrm{mg} / \mathrm{kg}, \mathrm{n}=4 /$ per group). $\mathrm{ZnPc}$ or saline were injected intraperitoneally. Rodent cages were partly covered with light-impermeable fabric. Body weight, behavior, food and water consumption were controlled each day. After sacrificing the animals on day 7, liver, kidney, and spleen were weighed to calculate the organ coefficient [rat weight $(\mathrm{g})$ /organ weight (g)] (23). The amount of white blood cells (WBC) in the blood was determined by using a hematology analyzer (Cell-Dyn 3700 , USA). Identification of leukocyte subsets (lymphocytes, monocytes, neutrophils, eosinophils) was performed by using Aerospray Slide Stainer 7120 (Wescor, USA). All animal experiments were conducted under the authority of the Local Ethics Committee for the Care and Use of Laboratory Animals of the Medical University of Gdansk, Poland.

\section{Results}

Uptake of ZnPc. Intracellular localization of increasing concentrations of $\mathrm{ZnPc}$ in cancer cells was investigated using confocal laser scanning microscopy. ZnPc-loaded Kyse-140 and OE-33 cells showed a dose-dependent uptake and homogenous cytoplasmic distribution of non-photoactivated $\mathrm{ZnPc}$ after $24 \mathrm{~h}$ of incubation (Fig. 1).

Determination of ZnPc-induced phototoxicity. Changes in the cell number of Kyse-140 and OE-33 cells after treatment with non- and photoactivated $\mathrm{ZnPc}(1-10 \mu \mathrm{M})$ were analyzed by crystal violet staining.

To establish the optimal loading time of $\mathrm{ZnPc}$, esophageal cancer cells were incubated for 1-30 h with rising concentrations of $\mathrm{ZnPc}(1-10 \mu \mathrm{M})$. The subsequent PDT $\left(10 \mathrm{~J} / \mathrm{cm}^{2}\right)$ showed a strong correlation between loading time and growth rate of ZnPc-PDT treated cells. The longer the incubation time, the more pronounced was the ZnPc-PDT induced growth inhibition, reaching its maximum after $24 \mathrm{~h}$ of incubation. No further increase was observed when the incubation time was prolonged to $30 \mathrm{~h}$. Squamous esophageal cancer cells (Kyse140) were more sensitive (Fig. 2A) than adenocarcinomatous OE-33 cells which required higher $\mathrm{ZnPc}$-concentrations for pronounced growth inhibitory effects (Fig. 2B). Additional experiments on Kyse-140 using the RTCA iCELLigence system (ACEA, Bioscences, USA), confirmed the proliferation data (24). This system monitors the proliferation of ZnPc-PDT treated cells in real-time. Photodynamic treatment caused a $68 \%$ decrease in the cell index (value calculated from changes in the electrical impedance, which correlates with changes in cell numbers) of cancer cells preincubated with $\mathrm{ZnPc}(5 \mu \mathrm{M})$ at least $24 \mathrm{~h}$ before PDT (data not shown).

To measure the time course of growth inhibition of ZnPc-PDT treated Kyse-140 and OE-33 cells (preincubated with $\mathrm{ZnPc}$ for $24 \mathrm{~h}$ ), cell proliferation was examined for up to $72 \mathrm{~h}$ after photoactivation of $\mathrm{ZnPc}$. Photoactivation of $\mathrm{ZnPc}$ $\left(10 \mathrm{~J} / \mathrm{cm}^{2}\right)$ resulted in a significant dose- and time-dependent decrease in cell proliferation of Kyse-140 (Fig. 3A) and OE-33 (Fig. 3B) of $>90 \%$ as compared to untreated control cells. The phototoxic effects of ZnPc-PDT was more pronounced in squamous Kyse-140 cancer cells than in adenocarcinomatous OE-33 cells, which is reflected in the respective $\mathrm{IC}_{50}$-values of $1.41 \pm 0.40 \mu \mathrm{M}$ (Kyse-140) and 3.35 $\pm 0.79 \mu \mathrm{M}$ (OE-33). Moreover, at least the Kyse-140 cells that escaped from being killed by low dose ZnPc-PDT $(1 \mu \mathrm{M})$ did not regenerate (re-proliferate) in the following days (Fig. 3A). 

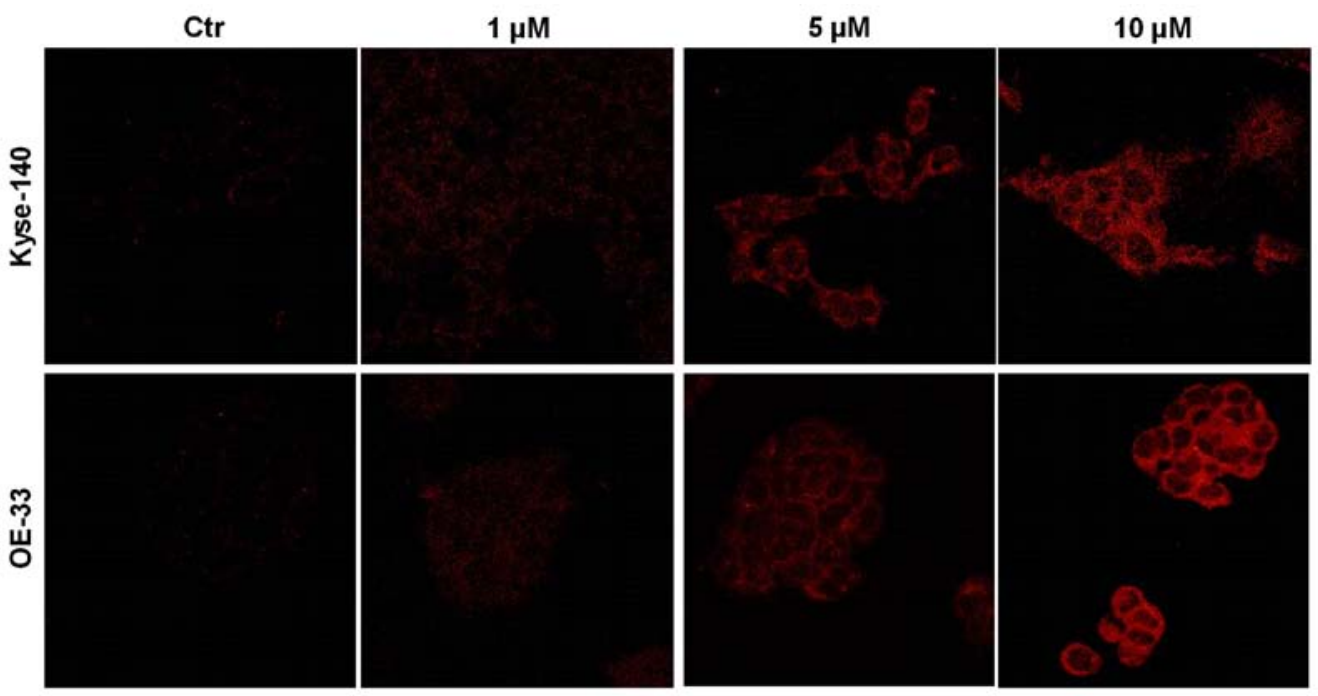

Figure 1. Dose-dependent uptake of ZnPc in esophageal cancer cells. Squamous (Kyse-140) and adenocarcinoma (OE-33) cells were incubated with rising concentrations $(1-10 \mu \mathrm{M})$ of $\mathrm{ZnPc}$ for $24 \mathrm{~h}$. ZnPc uptake was determined by fluorescence microscopy using a confocal laser scanning microscope (ex/em 633/400-800), In both cell lines, a dose-dependent, homogeneous cytoplasmic distribution was observed. Representative images of at least 3 independent experiments.

A

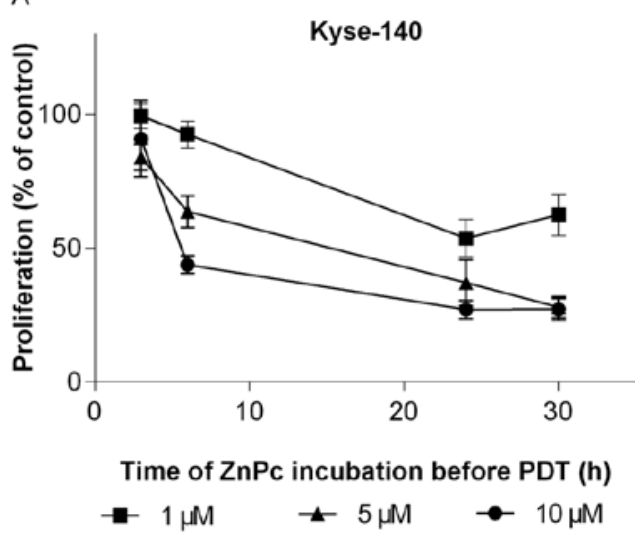

B

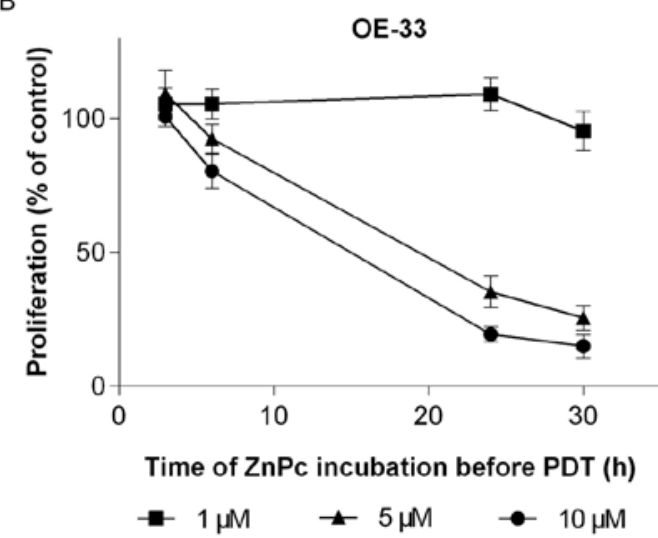

Figure 2. PDT effectiveness depends on the pre-incubation time of ZnPc. Esophageal cancer cells were incubated with rising concentration of ZnPc (1-10 $\mu \mathrm{M})$ for 1-30 h prior to PDT $\left(10 \mathrm{~J} / \mathrm{cm}^{2}\right)$. At each given concentration the effectiveness of the ZnPc-PDT strongly depended on pre-incubation time. The longer the incubation period, the more pronounced the growth inhibitory effect was. Kyse-140 (A) responded more sensitive than OE-33 cells (B). Growth inhibition was determined $24 \mathrm{~h}$ after ZnPc-PDT and is given as the percentage of untreated but illuminated controls, whose proliferation was set $100 \%$. Means \pm SEM of at least 3 independent experiments.
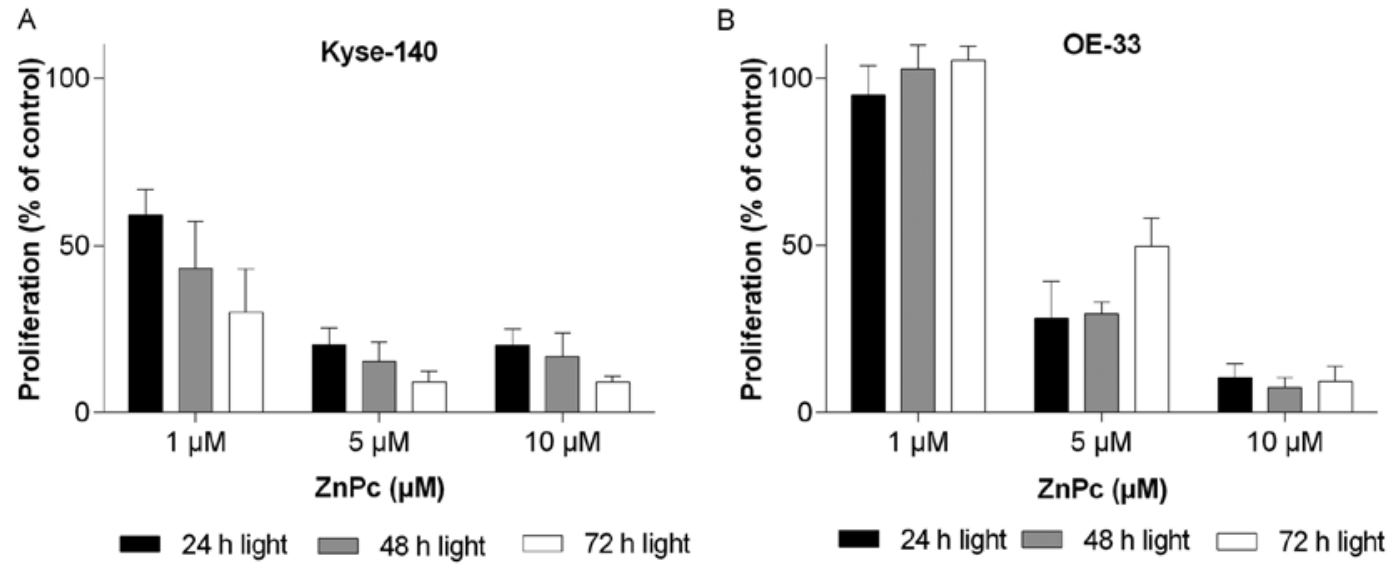

Figure 3 (A,B). ZnPc-PDT-induced growth inhibition of esophageal cancer cells. After $24 \mathrm{~h}$ of incubation with increasing concentrations of ZnPc esophageal cancer cells were illuminated with $10 \mathrm{~J} / \mathrm{cm}^{2}$ leading to a dose- and time-dependent growth inhibition of $>90 \%$ in esophageal squamous cell carcinoma cells (Kyse-140) and adenocarcinoma cells (OE-33). Data are given as the percentage of untreated but illuminated controls, whose proliferation was set $100 \%$. Means $\pm \mathrm{SD}$ of at least $\mathrm{n}=3$ independent experiments. 

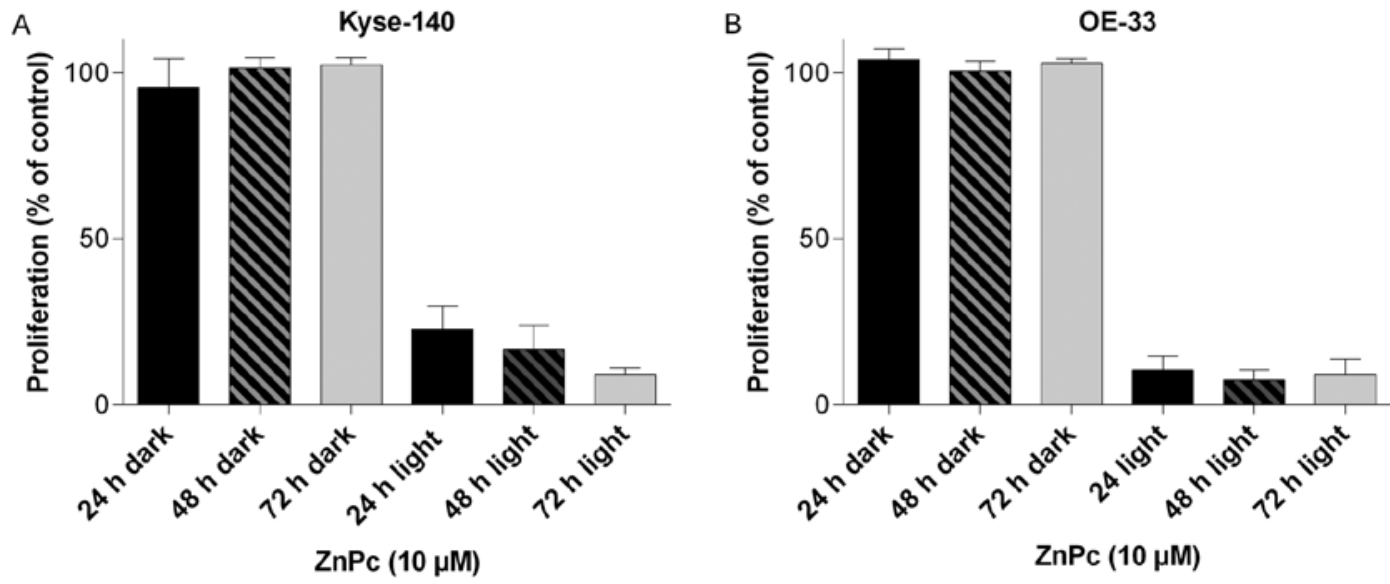

Figure 4. Non-photoactivated ZnPc does not affect cell proliferation. Kyse-140 (A) or OE-33 (B) cells were incubated with ZnPc (10 $\mu \mathrm{M} / 24$ h). After illumination with a light energy dose of $10 \mathrm{~J} / \mathrm{cm}^{2}$ (light) or without illumination (dark) the cells were grown for three days in an incubator $\left(37^{\circ} \mathrm{C}, 5 \% \mathrm{CO}_{2}\right)$. In contrast to photoactivated $\mathrm{ZnPc}$, which led to a marked decrease in cell proliferation of $\sim 90 \%$, non-photoactivated cells did not show any decrease or altered growth pattern, as compared to untreated controls. Data are given as the percentage (mean \pm SD) of the proliferation of untreated but illuminated controls, which was set at $100 \%$. Three independent experiments for each cell line were performed.

Checking for dark toxic effects of $\mathrm{ZnPc}$, changes in the cell number and morphology of Kyse-140 and OE-33 cells loaded with ZnPc (1-10 $\mu \mathrm{M})$ were determined for up to $72 \mathrm{~h}$ after the incubation period. Even at concentrations as high as $10 \mu \mathrm{M}$, no decrease in cell number (Fig. 4) nor changes in the morphology (data not shown) of either esophageal cancer cell model could be observed, showing the non-toxic nature of the non-illuminated compound.

Induction of ROS formation by ZnPc-PDT. One of the underlying mechanisms of photodynamic therapy is the generation of highly reactive oxygen species (ROS) and free radicals upon photoactivation of the PS, thereby damaging the membranes of the cell and its organelles (e.g., mitochondria, Golgi vesicles, ribosomes) which subsequently leads to severe cell injury and death. ZnPc-PDT-induced formation of ROS was evaluated by fluorescence microscopy employing dyes that monitor ROS formation in the cytoplasm (orange fluorescence) or in the nucleus/mitochondria (green fluorescence). Twenty-four hours after ZnPc-PDT a robust increase in ROS formation was observed in either Kyse-140 (Fig. 5) or OE-33 cells. ROS formation occurred ubiquitously and without a preferred localization in the nucleus or mitochondria, as in both cell lines there was a similar increase in ROS formation in the nucleus/mitochondria as well as in the cytoplasm. To further confirm ROS formation after ZnPc-PDT, Kyse-140 cells were incubated with the antioxidant and free radical scavenger vitamin C $(1 \mathrm{mM})$ prior to PDT. One hour preincubation with vitamin $\mathrm{C}$ caused an appreciable decrease of free radical formation in the cytoplasm as well as in the nucleus/mitochondria (Fig. 5).

Apoptotic effect of ZnPc-PDT. Photodynamic treatment can lead to the induction of apoptosis by ROS-mediated disturbance of mitochondrial integrity. The molecular mechanism underlying the ZnPc-PDT induced apoptosis and changes in cell morphology of Kyse-140 were analyzed for up to $6 \mathrm{~h}$ after PDT.
ZnPc-PDT caused time- and dose-dependent increase of caspase-3-activity, which was measured by performing caspase-3 assays. ZnPc-PDT treated cells showed an increase in caspase-3 activity of up to 15 -fold higher as compared to untreated, but illuminated control cells (Fig. 6A). Employing fluorescence microscopy apoptosis-related changes in cell morphology were determined $24 \mathrm{~h}$ after PDT. Cells appeared shrunken and unstructured with simultaneous formation of membrane-bound apoptotic bodies (Fig. 6B). As caspase-3 can be activated by either mitochondria-dependent or -independent signaling pathways, we checked the expression of Bax, Bcl-2 and cytochrome $c$ to confirm the hypothesis that PDT-induced apoptosis was mitochondria driven because of ROS induced disturbance of mitochondrial integrity. One hour after ZnPc-PDT the expression of antiapoptotic Bcl-2 decreased dose-dependently with a simultaneous increase of proapoptotic Bax. Three hours after ZnPc-PDT an increase in cytochrome $c$ expression was observed (Fig. 6C). Cytochrome $c$ is released from the mitochondrial intermembrane into the cytosol during apoptosis further indicating mitochondria-dependent apoptosis.

Antitumor and antiangiogenic activity of ZnPc-PDT in vivo. Antineoplastic effects of the novel ZnPc-PDT was studied in vivo by employing CAM-assays. Tumor plaques ( $1 \times 10^{6}$ cancer cells) grown from squamous cell carcinoma (Kyse-140) were inoculated onto the CAM of 7-day-old fertilized chicken eggs. The plaques got attached to the microvessel network of the CAM after $72 \mathrm{~h}$ and thereafter were topically treated with $\mathrm{ZnPc}(10 \mu \mathrm{M})$ for $24 \mathrm{~h}$ and illuminated $\left(10 \mathrm{~J} / \mathrm{cm}^{2}\right)$. Seventy-two hours post PDT, tumors were excised, photographed and changes in tumor volume was determined. Photodynamic treatment led to a significant reduction of tumor growth of $>70 \%$ after 3 days when compared to control experiments, in which the tumors were also illuminated with $10 \mathrm{~J} / \mathrm{cm}^{2}$ but treated with $\mathrm{NaCl}$ instead of $\mathrm{ZnPc}$ (Fig. 7).

The antiangiogenic effects of ZnPc-PDT on the microvessel formation were examined on the developing CAM for $\leq 72 \mathrm{~h}$ after treatment. An area of $5 \mathrm{~mm} \emptyset$ of 11-day-old CAMs was 


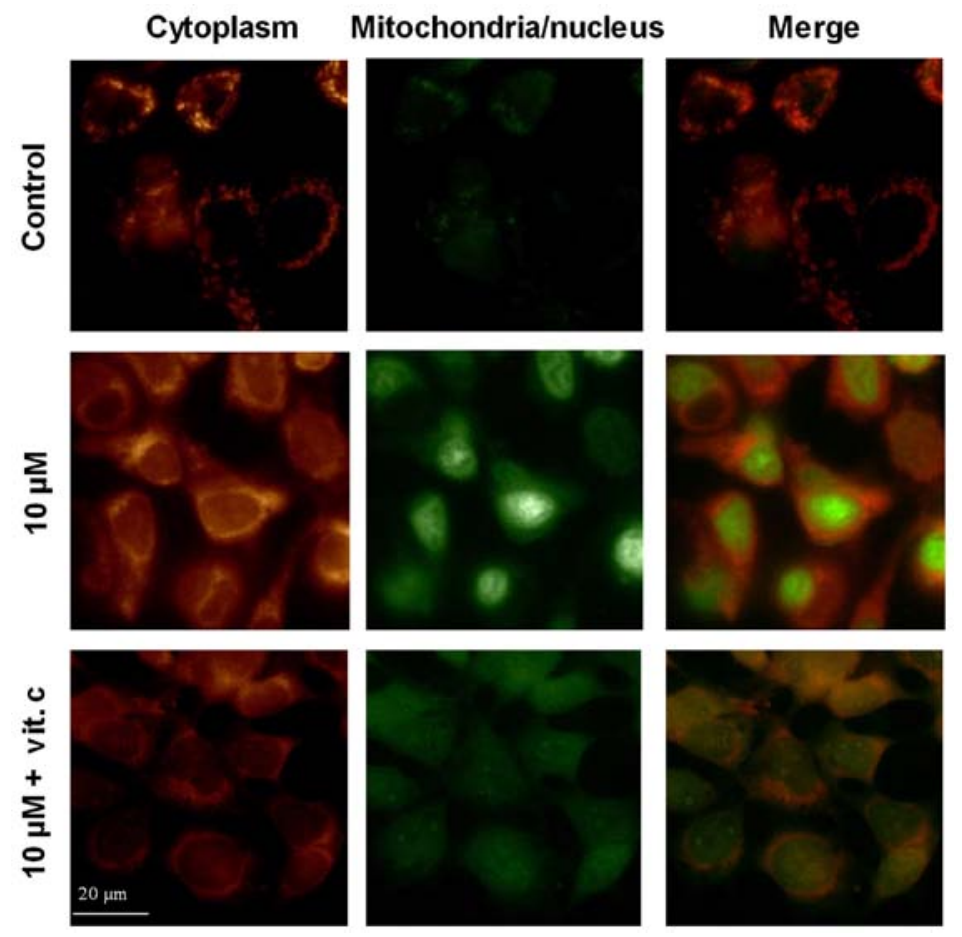

Figure 5. ZnPc-PDT-induced ROS formation in esophageal cancer cells. Kyse-140 cells were incubated with CellROX dyes to visualize free radical formation and localization in nucleus/mitochondria (green) or the cytoplasm (orange). Prominent increase in intracellular ROS was observed in both the nucleus/mitochondria as well as in the cytoplasm. Incubation with $1 \mathrm{mM}$ of the antioxidant vitamin C prior to PDT hampered ROS production (lower panel). Representative images of at least 3 independent experiments.

A

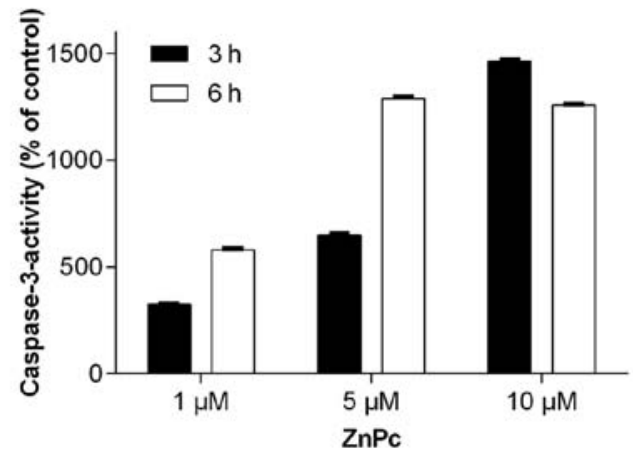

C

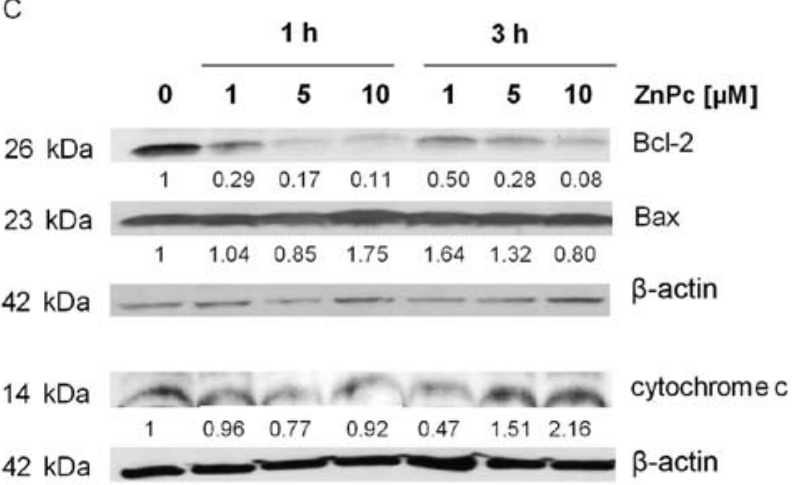

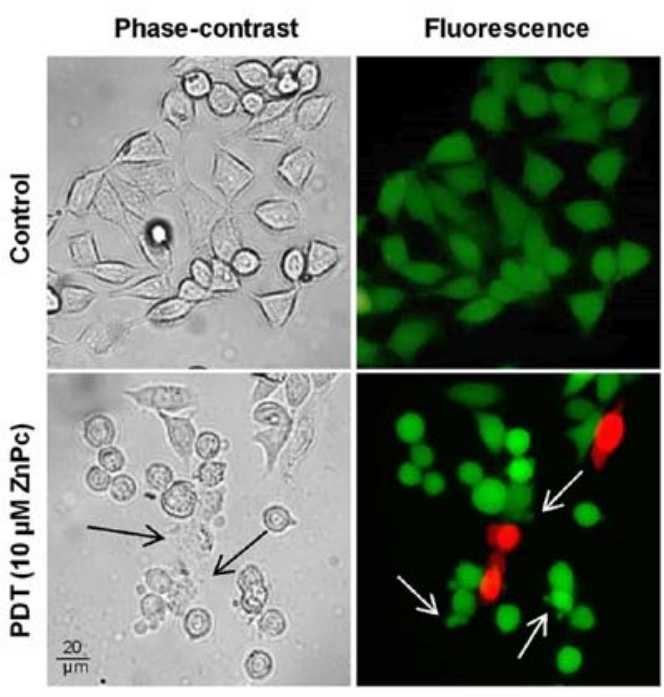

Figure 6. Induction of apoptosis by ZnPc-PDT. Kyse-140 cells were incubated for $24 \mathrm{~h}$ with rising concentrations of $\mathrm{ZnPc}$ and illuminated with $10 \mathrm{~J} / \mathrm{cm}^{2}$. (A) Dose-dependent increase in caspase- 3 activity of $\leq 15$-fold as compared to untreated but illuminated controls was observed after 3 and $6 \mathrm{~h}$ (means \pm SD of 3 independent experiments). (B) Apoptosis-specific morphological changes were determined by Live/dead-fluorescence microscopy. Six hours after ZnPc-PDT the formation of apoptotic bodies (white arrows) was observed. Moreover, the morphology of treated cells appeared shrunken and flat (black arrows), as compared to the controls. Viable cells are stained green, dead cells red. Representative tracings out of 3 independent experiments. (C) Dose-dependent downregulation of antiapoptotic Bcl-2 and concomitant upregulation of proapototic Bax occurred $1 \mathrm{~h}$ after ZnPc-PDT. Expression of cytochrome $c$ was increased $3 \mathrm{~h}$ after PDT, indicating mitochondria-driven apoptosis. Densitometrical analysis with ImageJ depicts the relative increase or decrease in protein expression of PDT-treated vs. untreated controls cells, whose expression was set at 1 . 
A

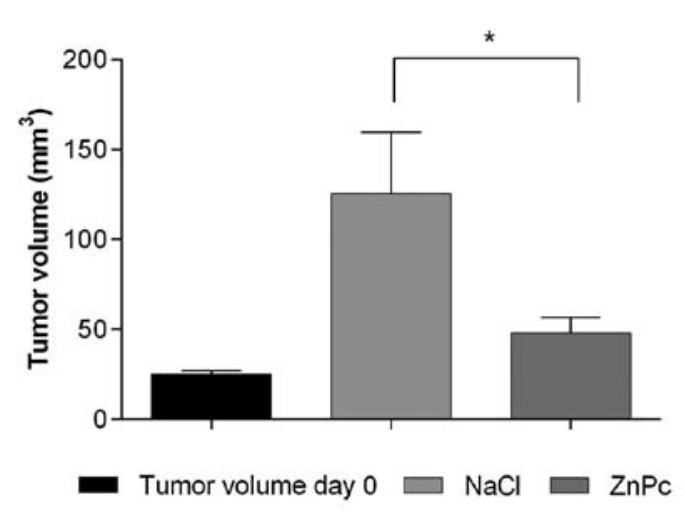

$B$

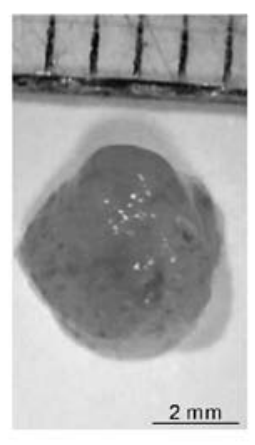

$\mathrm{NaCl}$

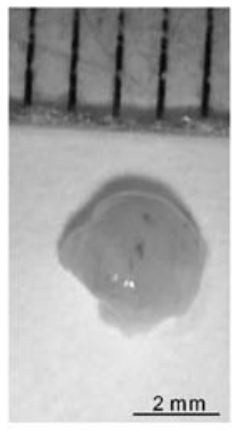

$\mathrm{ZnPc}(10 \mu \mathrm{M})$

Figure 7. Antineoplastic potency of ZnPc-PDT. Esophageal tumor plagues (Kyse-140) grown on the CAM of fertilized chicken eggs were incubated with ZnPc $(10 \mu \mathrm{M} / 24 \mathrm{~h})$ and illuminated $\left(10 \mathrm{~J} / \mathrm{cm}^{2}\right)$. (A) Seventy-two hours post PDT the ZnPc-PDT treated tumors were significantly smaller $(>70 \%)$ than the untreated, but illuminated control tumors ( $\mathrm{n}=6$; means \pm SEM; t-test, ${ }^{p} \mathrm{p}<0.001$ ). (B) Representative images of $\mathrm{NaCl}$ (control) or ZnPc-treated esophageal tumor plaques extracted from the CAM three days after PDT.

A

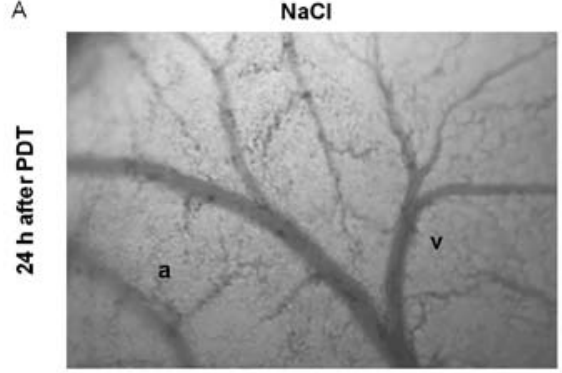

C

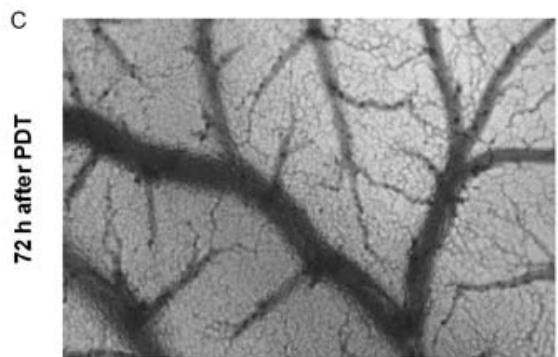

B

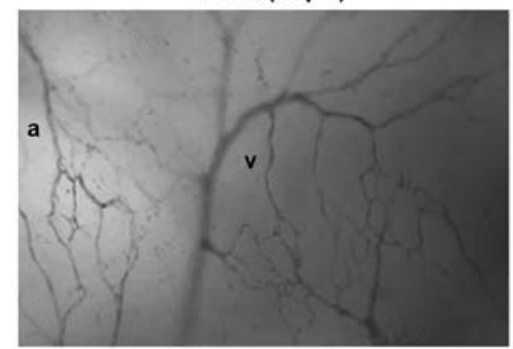

D

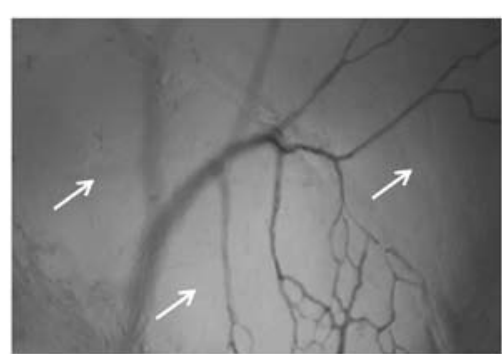

Figure 8. ZnPc-PDT causes long-lasting damage of the CAM vasculature. Ten microliters of ZnPc (10 $\mu \mathrm{M})$ were topically applied to the microvessel network of the CAM for $24 \mathrm{~h}$ and then illuminated with $10 \mathrm{~J} / \mathrm{cm}^{2}$. Three days after PDT no damage of the vasculature nor inhibited angiogenic sprouting was observed in NaCl-treated control CAMs (A and C), while ZnPc-PDT caused a marked and long-lasting vasodegeneration and reduced angiogenic sprouting leading to large non-perfused areas (arrows, B and D) after 24 and $72 \mathrm{~h}$ after PDT. a, artery; v, vein. Representative images of at least 3 independent experiments.

incubated with $10 \mu \mathrm{M} \mathrm{ZnPc}$ for $24 \mathrm{~h}$ and then illuminated $\left(10 \mathrm{~J} / \mathrm{cm}^{2}\right)$. ZnPc-PDT led to an increase of non-perfused areas and to vasodegeneration of the vasculature and the capillary plexus. $\mathrm{NaCl}$ treated and illuminated control CAMs showed no changes in the vascular network, which still consisted of a continuously perfused capillary plexus and larger vessels (arteries and veins). The antiangiogenic changes of ZnPc-PDT were still evident after $72 \mathrm{~h}$ indicating a lasting antiangiogenic effect of the treatment in vivo (Fig. 8).

Safety of non-illuminated $\mathrm{ZnPc}$ in vivo. Prior to animal experiments with the novel ZnPc-PDT, we performed a set of experiments evaluating the so-called 'dark toxicity' of the novel photosensitizer in vivo to get valuable information on its systemic effects in living organisms as well on its expected clinical safety.
Injection of $10 \mu \mathrm{lnPc}(10 \mu \mathrm{l}$ of $10 \mu \mathrm{M})$ into an embryofeeding vein of the chorioallantoic membrane at day 14 of embryonic development did not influence the survival or further embryonic development. Twenty-four hours after $\mathrm{ZnPc}$ injection, $100 \%$ of the 6 injected chicken embryos survived (data not shown), further supporting the expected safety of the novel photosensitizer in its non-photoactivated state.

Based on the promising in vitro findings (Fig. 4) and the aforementioned in vivo results, we performed first animal studies on Wistar rats. The rats were injected intraperitoneally with rising doses of $\mathrm{ZnPc}(0.5-5 \mathrm{mg} / \mathrm{kg})$ and kept in light-protected rodent cages for one week. During the entire observation period the animals constantly kept or even slightly gained weight (Fig. 9A), behaved normally, and did not show any changes in food and water consumption, as compared to the saline treated control animals. At the end of the experiment, several 
A

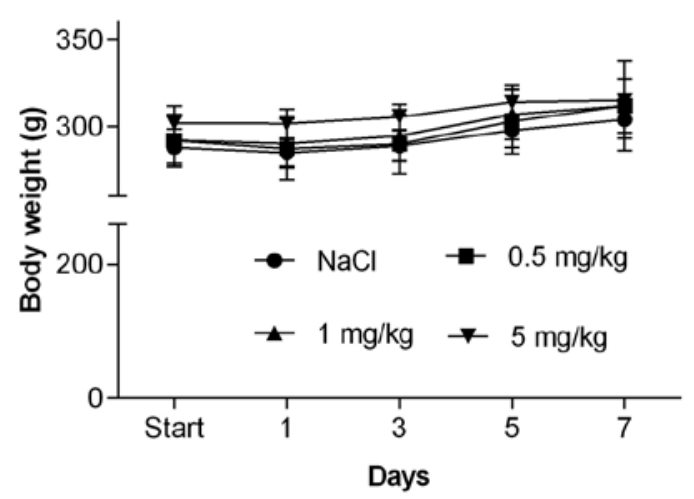

B

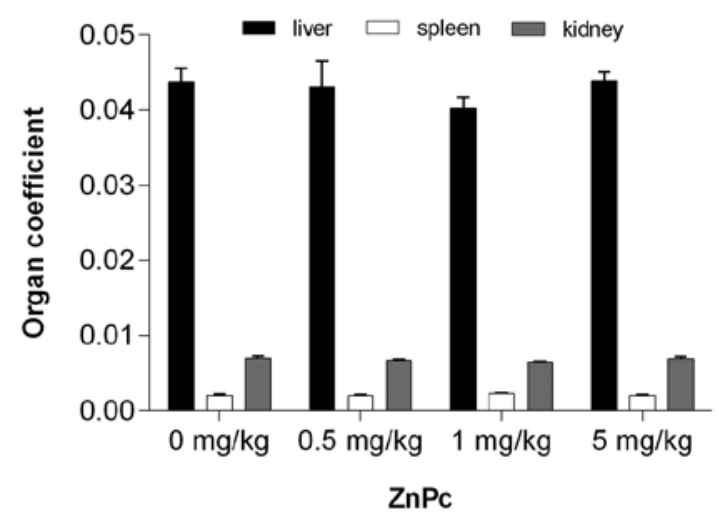

Figure 9. Non-photoactivated $\mathrm{ZnPc}$ is non-toxic in vivo. Animals were injected peritoneally with increasing doses of $\mathrm{ZnPc}(0.5-5 \mathrm{mg} / \mathrm{kg})$ or $\mathrm{NaCl}(0.9 \%)$ and were kept in light-protected cages. (A) Continuous monitoring of the weight of the animals showed that they constantly kept or even slightly gained weight, as expected for these young animals, which were still in their growth phase. (B) The organ coefficient is the ratio of the total weight of an animal divided by the weight of a respective organ (liver, spleen, kidney). No significant differences in the organ coefficient of liver spleen and kidney were observed between control animals and ZnPc-treated animals, indicating that the organs did not become edematous or shrunken upon the treatment, underlining the non-toxic character of non-illuminated $\mathrm{ZnPc}$. Mean values $\pm \mathrm{SD}$ of at least 3/group.

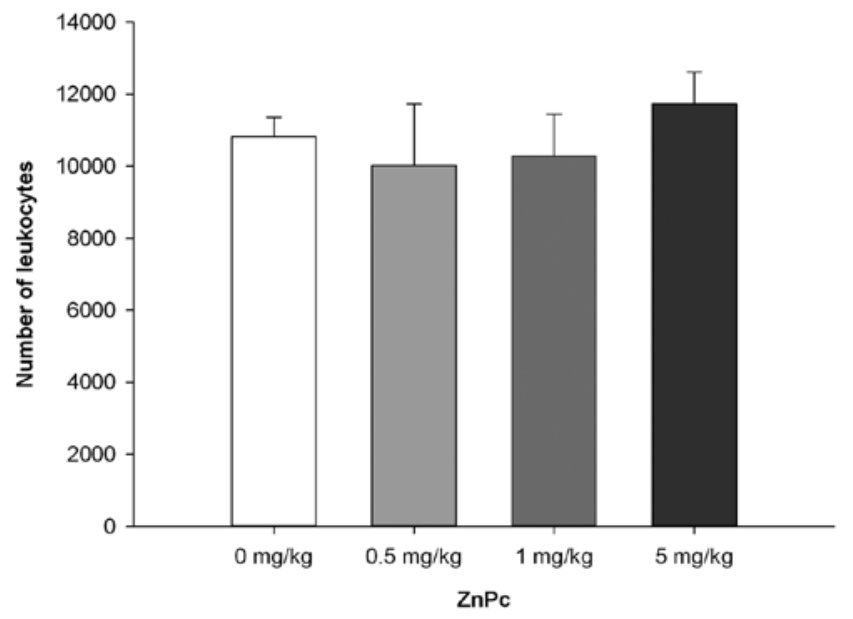

Figure 10. Non-photoactivated $\mathrm{ZnPc}$ does not induce systemic inflammation. Without photoactivation no significant change in the number of leukocytes of ZnPc-treated animals was observed, suggesting that the intraperitoneal injection of increasing doses of non-photoactivated $\mathrm{ZnPc}(0.5-5 \mathrm{mg} / \mathrm{kg})$ does not induce any systemic inflammation. Means \pm SD of at least 3 animals/ group.

organs (liver, spleen, and kidney) were removed and weighed, also blood samples were taken for blood analysis. None of the analyzed organs were swollen or shrunken which is reflected by the constant organ coefficient (Fig. 9B). No significant changes in leukocyte number (Fig. 10) or leukocyte subsets (data not shown) of photosensitizer-treated animals were observed, indicating that non-photoactivated $\mathrm{ZnPc}$ is generally well-tolerated and does not induce systemic inflammation.

\section{Discussion}

Medical therapy of advanced esophageal cancer is still unsatisfactory. Moreover, many patients with esophageal cancer are in poor clinical condition precluding aggressive chemotherapy (5). Thus, there is a strong need for new, effective and well-tolerated treatment approaches. An interesting alternative approach may be photodynamic therapy (PDT) which is already in clinical use for the treatment of Barret's dysplasia and esophageal cancer (25-28). Besides elimination of the neoplastic tissue, PDT treatment may also decrease the risk of esophageal stricture and perforation. Moreover, technological improvements (e.g., light emitting fabrics or optical fibers), enabled a rapid progress in the field of PDT (29). However, there is still a need for new and highly effective photosensitizers. In a previous study we proposed tetra-triethyleneoxysulfonylsubstituted zinc phthalocyanine as a promising photosensitizer for photodynamic treatment of different types of gastrointestinal cancer (14). In this study, we focused on the suitability and effectiveness of a PDT treatment with the novel $\mathrm{ZnPc}$ in human esophageal cancer of either adenocarcinomatous or squamous cell carcinomatous histology.

PDT efficiency is highly dependent on the photophysical properties of the employed PS as well as on its intracellular accumulation and distribution in the target cells/tissue $(30,31)$. For example, Shao et al and Tynga et al showed that comparable $\mathrm{ZnPc}$ primarily accumulates in mitochondria and lysosomes $(32,33)$. Employing confocal laser microscopy, we could demonstrate a time- and dose-dependent uptake of non-photoactivated $\mathrm{ZnPc}$ in esophageal cancer cells of both entities. However, in contrast to the above-mentioned studies, we observed rather homogeneous cytoplasmic distribution of PS in both cell lines. Nonetheless, photoactivation of ZnPc caused ROS formation not only in the cytoplasm but also in mitochondria and nucleus, pointing to its high phototoxic potential.

The particular PDT protocols have a great impact on the therapy outcome and differ from one cancer type to another $(34,35)$. The time interval between the application of a photosensitizer and subsequent PDT is very important due to the different intracellular uptake kinetics of each particular photosensitizer (36). To estimate the optimal incubation time of $\mathrm{ZnPc}$ in esophageal cancer cells, different pre-incubation times (1-30 h) were evaluated. We could show 
that approximately $24 \mathrm{~h}$ were required to achieve pronounced antineoplastic PDT-effects with ZnPc concentrations as low as $1 \mu \mathrm{M}$ in EC cells. Prolonging the incubation time to $>24 \mathrm{~h}$ did not further enhance the PDT outcome at this concentration, but the data also showed that at higher concentrations of the PS $(5 \mu \mathrm{M})$ comparable results were achieved with much shorter pre-incubation times of only $10 \mathrm{~h}$. Thus for the determination of optimal treatment protocols for patients, it will be interesting to figure out the reasonable compromise between a preferably short preincubation time and a well-tolerated but still highly effective PS concentration.

To estimate the cytotoxic potential of ZnPc-PDT, proliferation studies were performed. We observed a significant decrease in the cell number of esophageal adeno- and squamous cell carcinoma cells of $\geq 90 \%$ after ZnPc-PDT, showing that the treatment is working well in both histologies. Kyse140 cells seemed to be even more susceptible to the treatment, as shown by the lower $\mathrm{IC}_{50}$-value of $\mathrm{ZnPc}$ of $1.41 \mu \mathrm{M}$, as compared to $3.35 \mu \mathrm{M}$ in OE-33 cells. Another difference between squamous and adenocarcinoma cells became apparent when looking at the longevity of the PDT-induced growth inhibition. While squamous Kyse-140 cells which escaped from being immediately killed by the initial PDT treatment did not seem to be able to (re-)proliferate in the following days, PDT-surviving adenocarcinomatous OE-33 cells started to re-grow $48 \mathrm{~h}$ after treatment. This effect could be compensated by using higher concentrations of PS for the specific cell line. Further studies are required to reveal if specific cellular responses e.g., cell cycle regulation might play a role in the different behavior of the two cell types and the respective mode of action.

Generation and localization of free radicals and singlet oxygen species have a strong influence on the efficiency of PDT (37). Here, we demonstrated ROS formation in esophageal cancer cells by ZnPc-PDT for the first time. By employing green and orange fluorescent dyes, which distinguish between free radical formation and localization in the cytoplasm (orange) or cell organelles such as the mitochondria or the nucleus (green), we observed a dose-dependent production of ROS after ZnPc-PDT in both esophageal carcinoma entities. Prominent increases in the ROS production of Kyse-140 and OE-33 cells resulted in cell death rates of 70-90\% already $24 \mathrm{~h}$ after PDT. The increase in green fluorescence indicates ROS formation near or in the nucleus and mitochondria. This notion may be of importance when deciphering the underlying signaling events and pathways of ZnPc-PDT in terms of apoptosis (38). Nucleus and mitochondria specific ROS formation was partially blocked by pre-incubation with the antioxidant vitamin $\mathrm{C}$, supporting the idea that ROS formation may be of particular importance for the antiproliferative effects of the novel photosensitizer. This is consistent with the findings of Grimm et al who investigated the influence of different exogenous antioxidants on melanoma cell proliferation after PDT with 5-aminolevulinic acid (5-ALA) (39). After exposure to 5-ALA, human melanoma cells were incubated with vitamin $C$ at different doses and then irradiated with light followed by a significant decrease of the cell death rate.

In the last decade, a significant progress has been made in the development of apoptosis-modulating cancer therapeutics which are currently examined in several human clinical trials (40). Most importantly, the induction of apoptosis, unlike necrosis, does not cause inflammation and is thus preferred over cytotoxic and necrotic treatment strategies $(30,41)$. It has been shown that PDT can induce apoptosis and in a previous study we demonstrated that ZnPc-PDT induced apoptotic cell death of gastrointestinal cancer cells. However, it was unclear whether extrinsic or intrinsic apoptotic pathways were involved (14). In this study we investigated the changes in the expression of proteins associated with mitochondria-driven apoptosis. Photoactivated $\mathrm{ZnPc}$ caused a downregulation of antiapoptotic Bcl-2 and a concomitant upregulation of proapoptotic Bax. Importantly, an increase in cytochrome $c$ was detected. Together with the marked increase in caspase-3 activity, the data indicated that ZnPc-PDT induces a mitochondria-dependent, intrinsic induction of apoptosis in esophageal cancer cells (38).

The main goal of PDT treatment is the elimination of the neoplastic tissue. Numerous studies on new photosensitizers showed their efficiency to eliminate cancer cells in vitro $(33,42,43)$. However, the therapeutic potential and suitability of a new PS can only be assessed in a combination of in vitro and respective in vivo studies. In our in vivo model (CAM-assay), we showed strong antitumor effects of photoactivated $\mathrm{ZnPc}$ on esophageal tumor plaques, which were significantly smaller $(>70 \%)$ than ZnPc-untreated control tumors (44). Based on the encouraging data, it is at least conceivable that $\mathrm{ZnPc}-\mathrm{PDT}$ will show equivalent effectiveness in animal models.

Destructive effects of PDT on the microvasculature are well known and have been successfully used for the treatment of choroidal neovascularization or age-related macular degeneration $(45,46)$. In oncology, damage of tumor vascularity and blood flow stasis are significant aspects of PDT that contribute to tumor regression (47). However, it has been reported by Weiss et al that PDT-damaged vasculature can regenerate within $48 \mathrm{~h}$ after PDT $(21,45)$. Here, we also demonstrated that ZnPc-PDT exerts a destructive influence on the blood vessel formation and the microvasculature, but in contrast to the findings by Weiss et al these effects were comparably long-lasting, as even $72 \mathrm{~h}$ after treatment no regeneration of the vascular network of the CAM could be observed. Long-lasting antiangiogenic effects of enhanced PDT-treatment with ZnPc may be of particular importance if looking for suitable combination treatments in which the PDT is combined with chemotherapeutics that are antiangiogenic or whose antineoplastic potency depends on an antiangiogenic environment (48).

Last but not least, clinical safety, good tolerability and absence of toxicity in its non-photoactivated state (dark toxicity) are important features of appropriate photosensitizers. Checking for dark toxic effects of the novel $\mathrm{ZnPc}$ in vitro and in vivo, we showed that non-photoactivated $\mathrm{ZnPc}$ does not affect cell survival or proliferation nor does it exhibit any sign of toxicity in in vivo experiments. Testing embryonic survival of fertilized chicken eggs after intravenous application of $\mathrm{ZnPc}$ did not lead to signs of toxicity either. Embryonic development as well as survival was not even affected by the highest doses of ZnPc. In line with comparable results of Zhang et al, who investigated dark toxic effects of phthalocyanines we felt encouraged to perform first animal tests (22). Young Wistar rats injected with $\mathrm{ZnPc}(0.5-5 \mathrm{mg} / \mathrm{kg}$ bodyweight $) \mathrm{did}$ 
not show signs of dark toxicity or incompatibility towards the non-photoactivated compound. All animals behaved normally, did not show changes in water or food consumption and did not lose but even slightly gained weight during the experiment. Even more important, the white blood cell count of ZnPc-treated animals did not differ significantly from control animals. Moreover, no changes in the organ coefficients were observed, indicating that no inflammatory processes or organ specific disturbances occurred. Taken together, the novel photosensitizer ZnPc appears to have an excellent biotolerability thus rendering it an interesting photosensitizer for further in vivo studies.

In conclusion, in this study we showed the extraordinary potential of ZnPc for PDT-treatment of esophageal cancer. Further in vivo investigations are warranted to estimate antitumor activity of photoactivated $\mathrm{ZnPc}$ in animal models.

\section{Acknowledgements}

Weronika Kuzyniak was funded by a scholarship of the Studienstiftung des deutschen Volkes. Gustav Steinemann was supported by a scholarship of the FAZIT-Stiftung, Frankfurt a. M., Germany. Jacob Schmidt was funded by a scholarship of the Berliner Krebsgesellschaft e.V.

\section{References}

1. Thrift AP: The epidemic of oesophageal carcinoma: Where are we now? Cancer Epidemiol 41: 88-95, 2016.

2. Ireland CJ, Thompson SK, Laws TA and Esterman A: Risk factors for Barrett's esophagus: A scoping review. Cancer Causes Control 27: 301-323, 2016.

3. Meves V, Behrens A and Pohl J: Diagnostics and early diagnosis of esophageal cancer. Viszeralmedizin 31: 315-318, 2015.

4. Chang YL, Tsai YF, Chao YK and Wu MY: Quality-of-life measures as predictors of post-esophagectomy survival of patients with esophageal cancer. Qual Life Res 25: 465-475, 2016.

5. Sutter AP, Höpfner M, Huether A, Maaser K and Scherübl H: Targeting the epidermal growth factor receptor by erlotinib (Tarceva) for the treatment of esophageal cancer. Int J Cancer 118: 1814-1822, 2006.

6. Triesscheijn M, Baas P, Schellens JHM and Stewart FA: Photodynamic therapy in oncology. Oncologist 11: 1034-1044, 2006.

7. Yi E, Yang CK, Leem C, Park Y, Chang J-E, Cho S and Jheon S: Clinical outcome of photodynamic therapy in esophageal squamous cell carcinoma. J Photochem Photobiol B 141: 20-25, 2014.

8. Shishkova N, Kuznetsova O and Berezov T: Photodynamic therapy in gastroenterology. J Gastrointest Cancer 44: 251-259, 2013.

9. Höpfner M, Maaser K, Theiss A, Lenz M, Sutter AP, Kashtan H, von Lampe B, Riecken EO, Zeitz M and Scherübl H: Hypericin activated by an incoherent light source has photodynamic effects on esophageal cancer cells. Int J Colorectal Dis 18: 239-247, 2003.

10. Castano AP, Demidova TN and Hamblin MR: Mechanisms in photodynamic therapy: Part one-photosensitizers, photochemistry and cellular localization. Photodiagn Photodyn Ther 1: 279-293, 2004

11. Liu M, Tai C, Sain M, Hu AT and Chou F: Photodynamic applications of phthalocyanines. J Photochem Photobiol Chem 165: 131-136, 2004.

12. Josefsen LB and Boyle RW: Photodynamic therapy: Novel thirdgeneration photosensitizers one step closer? Br J Pharmacol 154: $1-3,2008$.

13. Jiang Z, Shao J, Yang T, Wang J and Jia L: Pharmaceutical development, composition and quantitative analysis of phthalocyanine as the photosensitizer for cancer photodynamic therapy. J Pharm Biomed Anal 87: 98-104, 2014.
14. Kuzyniak W, Ermilov EA, Atilla D, Gürek AG, Nitzsche B, Derkow K, Hoffmann B, Steinemann G, Ahsen V and Höpfner M: Tetra-triethyleneoxysulfonyl substituted zinc phthalocyanine for photodynamic cancer therapy. Photodiagn Photodyn Ther 13: 148-157, 2016.

15. Atilla D, Saydan N, Durmuş M, Gürek AG, Khan T, Rück A, Walt $\mathrm{H}$, Nyokong $\mathrm{T}$ and Ahsen V: Synthesis and photodynamic potential of tetra- and octa-triethyleneoxysulfonyl substituted zinc phthalocyanines. J Photochem Photobiol Chem 186: 298-307, 2007.

16. Nitzsche B, Gloesenkamp C, Schrader M, Ocker M, Preissner R, Lein M, Zakrzewicz A, Hoffmann B and Höpfner M: Novel compounds with antiangiogenic and antiproliferative potency for growth control of testicular germ cell tumours. Br J Cancer 103: $18-28,2010$.

17. Gloesenkamp C, Nitzsche B, Lim AR, Normant E, Vosburgh E, Schrader M, Ocker M, Scherübl H and Höpfner M: Heat shock protein 90 is a promising target for effective growth inhibition of gastrointestinal neuroendocrine tumors. Int J Oncol 40: $1659-1667,2012$.

18. Höpfner M, Huether A, Sutter AP, Baradari V, Schuppan D and Scherübl H: Blockade of IGF-1 receptor tyrosine kinase has antineoplastic effects in hepatocellular carcinoma cells. Biochem Pharmacol 71: 1435-1448, 2006.

19. Huether A, Höpfner M, Baradari V, Schuppan D and Scherübl H: Sorafenib alone or as combination therapy for growth control of cholangiocarcinoma. Biochem Pharmacol 73: 1308-1317, 2007.

20. Nitzsche B, Gloesenkamp C, Schrader M, Hoffmann B Zengerling $F$, Balabanov $S$, Honecker $F$ and Höpfner $M$ : Anti-tumour activity of two novel compounds in cisplatinresistant testicular germ cell cancer. Br J Cancer 107: 1853-1863, 2012.

21. Weiss A, van Beijnum JR, Bonvin D, Jichlinski P, Dyson PJ, Griffioen AW and Nowak-Sliwinska P: Low-dose angiostatic tyrosine kinase inhibitors improve photodynamic therapy for cancer: Lack of vascular normalization. J Cell Mol Med 18: 480-491, 2014.

22. Zhang Z, Jin H, Bao J, Fang F, Wei J and Wang A: Intravenous repeated-dose toxicity study of $\mathrm{ZnPcS} 2 \mathrm{P} 2$-based-photodynamic therapy in Wistar rats. Photochem Photobiol Sci 5: 1006-1017, 2006.

23. Tiwari DK, Jin T and Behari J: Bio-distribution and toxicity assessment of intravenously injected anti-HER 2 antibody conjugated CdSe/ZnS quantum dots in Wistar rats. Int J Nanomed 6: 463-475, 2011.

24. Gloesenkamp CR, Nitzsche B, Ocker M, Di Fazio P, Quint K, Hoffmann B, Scherübl $\mathrm{H}$ and Höpfner M: AKT inhibition by triciribine alone or as combination therapy for growth control of gastroenteropancreatic neuroendocrine tumors. Int J Oncol 40: 876-888, 2012.

25. Huang Z: A review of progress in clinical photodynamic therapy. Technol Cancer Res Treat 4: 283-293, 2005.

26. Fayter D, Corbett M, Heirs M, Fox D and Eastwood A: A systematic review of photodynamic therapy in the treatment of pre-cancerous skin conditions, Barrett's oesophagus and cancers of the biliary tract, brain, head and neck, lung, oesophagus and skin. Health Technol Assess 14: 1-288, 2010.

27. Rodrigues JR, Charris J, Ferrer R, Gamboa N, Angel J, Nitzsche B, Hoepfner M, Lein M, Jung K and Abramjuk C: Effect of quinolinyl acrylate derivatives on prostate cancer in vitro and in vivo. Invest New Drugs 30: 1426-1433, 2012.

28. Qumseya BJ, David W and Wolfsen HC: Photodynamic therapy for Barrett's esophagus and esophageal carcinoma. Clin Endose 46: 30-37, 2013.

29. Mordon S, Cochrane C, Tylcz JB, Betrouni N, Mortier L and Koncar V: Light emitting fabric technologies for photodynamic therapy. Photodiagn Photodyn Ther 12: 1-8, 2015.

30. Oleinick NL, Morris RL and Belichenko I: The role of apoptosis in response to photodynamic therapy: What, where, why, and how. Photochem Photobiol Sci 1: 1-21, 2002.

31. Morgan J, Potter WR and Oseroff AR: Comparison of photodynamic targets in a carcinoma cell line and its mitochondrial DNA-deficient derivative. Photochem Photobiol 71: 747-757, 2000.

32. Shao J, Dai Y, Zhao W, Xie J, Xue J, Ye J and Jia L: Intracellular distribution and mechanisms of actions of photosensitizer Zinc(II)-phthalocyanine solubilized in Cremophor EL against human hepatocellular carcinoma HepG2 cells. Cancer Lett 330: 49-56, 2013. 
33. Tynga IM, Houreld NN and Abrahamse H: The primary subcellular localization of Zinc phthalocyanine and its cellular impact on viability, proliferation and structure of breast cancer cells (MCF-7). J Photochem Photobiol B 120: 171-176, 2013.

34. Nanashima A, Isomoto H, Abo T, Nonaka T, Morisaki T, Arai J, Takagi K, Ohnita K, Shoji H, Urabe S, et al: How to access photodynamic therapy for bile duct carcinoma. Ann Transl Med 2: 23 2014.

35. Huang Z, Hsu Y, Li L, Wang L, Song X-D, Yow CMN, Lei X, Musani AI, Luo R-C and Day BJ: Photodynamic therapy of cancer - Challenges of multidrug resistance. J Innov Opt Health Sci 8: 1530002, 2015

36. Juarranz A, Jaén P, Sanz-Rodríguez F, Cuevas J and González S: Photodynamic therapy of cancer. Basic principles and applications. Clin Transl Oncol 10: 148-154, 2008

37. Gupta SC, Hevia D, Patchva S, Park B, Koh W and Aggarwal BB: Upsides and downsides of reactive oxygen species for cancer: The roles of reactive oxygen species in tumorigenesis, prevention, and therapy. Antioxid Redox Signal 16: 1295-1322, 2012.

38. Nowis D, Makowski M, Stokłosa T, Legat M, Issat T and Gołab J: Direct tumor damage mechanisms of photodynamic therapy. Acta Biochim Pol 52: 339-352, 2005.

39. Grimm S, Mvondo D, Grune T and Breusing N: The outcome of 5-ALA-mediated photodynamic treatment in melanoma cells is influenced by vitamin $\mathrm{C}$ and heme oxygenase-1. Biofactors 37 : 17-24, 2011.

40. Nicholson DW: From bench to clinic with apoptosis-based therapeutic agents. Nature 407: 810-816, 2000.
41. Abrahamse $\mathrm{H}$ and Hamblin MR: New photosensitizers for photodynamic therapy. Biochem J 473: 347-364, 2016.

42. Moeno S, Krause RWM, Ermilov EA, Kuzyniak W and Höpfner M: Synthesis and characterization of novel zinc phthalocyanines as potential photosensitizers for photodynamic therapy of cancers. Photochem Photobiol Sci 13: 963-970, 2014.

43. Wang A, Li Y, Zhou L, Yuan L, Lu S, Lin Y, Zhou J and Wei S: Charge dependent photodynamic activity of alanine based zinc phthalocyanines. J Photochem Photobiol B 141: 10-19, 2014.

44. Vargas A, Zeisser-Labouèbe M, Lange N, Gurny R and Delie F The chick embryo and its chorioallantoic membrane (CAM) for the in vivo evaluation of drug delivery systems. Adv Drug Deliv Rev 59: 1162-1176, 2007.

45. Nowak-Sliwinska $P$, van Beijnum JR, van Berkel $M$, van den Bergh $\mathrm{H}$ and Griffioen AW: Vascular regrowth following photodynamic therapy in the chicken embryo chorioallantoic membrane. Angiogenesis 13: 281-292, 2010.

46. Chan WM, Lim TH, Pece A, Silva R and Yoshimura N: Verteporfin PDT for non-standard indications - a review of current literature. Graefes Arch Clin Exp Ophthalmol 248: 613-626, 2010.

47. Fingar VH, Kik PK, Haydon PS, Cerrito PB, Tseng M, Abang E and Wieman TJ: Analysis of acute vascular damage after photodynamic therapy using benzoporphyrin derivative (BPD). Br J Cancer 79: 1702-1708, 1999.

48. Fukumura D and Jain RK: Tumor microvasculature and microenvironment: Targets for anti-angiogenesis and normalization. Microvasc Res 74: 72-84, 2007. 